\title{
Extending a geographic lens towards climate justice, part 2: climate action
}

\author{
Authors: \\ Morey Burnham, Department of Environment and Society, Utah State University \\ Claudia Radel,* Department of Environment and Society, Utah State University \\ Zhao Ma, Department of Environment and Society, Utah State University \\ Ann Laudati, School of Geographical Sciences, University of Bristol \\ *Corresponding author \\ 5215 Old Main Hill, Logan, UT 84322-5215; tel. 435-797-0516; email claudia.radel@usu.edu
}

\section{Citation:}

Burnham, M., Radel, C., Ma, Z., \& Laudati, A. (2013). Extending a geographic lens towards climate justice, part 2: climate action. Geography Compass, 7(3), 228-238.

\begin{abstract}
:
There has been a recent increase of interest within the academic literature on the justice issues posed by climate change and the human responses to its present and forecasted effects. In two parts (here and in a previous article), we review and synthesize the recent literature by asking what climate justice concerns have been identified within three related realms: 1) the characterization of climate change itself and the assignment of responsibility for that change; 2 ) the differential or uneven impacts of climate change; and 3) the actions taken to address the problems associated with climate change, including both mitigation and adaptation. Here in Part 2, we focus on the justice concerns of climate action, examining the scholarship on climate change mitigation mechanisms formulated at the international level (i.e., REDD+, CDM) and climate change adaptation projects and finance. We argue that geographers are wellpositioned to conduct (and already well engaged in) research on the local climate justice paradoxes emerging from the currently uncritical focus of climate action policy on justice at the level of the national state.
\end{abstract}




\section{Introduction}

There has been a recent increase of interest within the academic literature on the justice issues posed by climate change and the human responses to its present and forecasted effects. This literature is partially shaped by debates from environmental justice scholarship, but also has roots in various subfields of geography. Generally speaking, the field of geography offers unique understanding of the human-environment relationship based on an historical engagement with the spatiality and scale of environmental change and corresponding human responses. Therefore, as we shall argue, geographers are well-positioned to conduct research to examine the local climate justice paradoxes emerging from the currently uncritical focus of climate policy on justice at the level of the national state.

Within global climate action policy, climate justice has been conceptualized as a matter among state actors, resulting in various contradictory justice outcomes. It is here that we particularly see empirical research in geography contributing to a broader scholarly understanding of climate justice. Climate negotiation among national states focuses on justice questions at one particular scale, with states (and not communities, households, or individuals) as the parties of justice consideration. As Kythreotis (2011) argues, national states engage in climate negotiations on the basis of territorial and accumulation interests, which relate to concerns of sovereignty, boundaries, and material resources. As we stated in Part 1, questions of justice at this scale have become cemented largely into a "developed nation-developing nation" binary (Kythreotis 2011), with small island states presenting a discursively important (Farbotko and Lazrus 2012) third position. These available state subject positions have acted to veil the differences among actors at sub-national scales. And national states cannot be assumed to pay adequate attention to sub-state justice considerations. Consequently, concern is now emerging over the impacts of society's responses to climate change, through mitigation and adaptation action, on local livelihoods, rights, and identities (Marino \& Ribot 2012).

Our two-part review outlines the broad contours of and contradictions within the current climate justice debate, paying particular attention to justice questions at various analytic scales, with an eye towards cross-scalar issues. In Part 1, we briefly summarized the types of justice central to the debate, and these types of justice (distributive, procedural, and recognition) are important to the discussion here in Part 2 as well. We then reviewed two of the three core categories of justice dilemmas: the characterization of climate change and climate change impacts. Here in Part 2, we review the third core category of justice dilemmas: societal responses to climate change, or climate action. In particular, we focus on mitigation and adaptation action. We argue that current climate action policy adopts an uncritically global conception of justice focusing on state actors, which ignores local impacts and alienates local rights. The empirical work of geographers has been and will continue to be especially important in exposing the resultant climate justice paradoxes.

\section{Justice and Mitigation Action through Carbon Offset Projects}

Actions taken to address global climate change pose a particular set of justice problems and have been receiving growing attention in geography. Many of these actions fall under the narrative of "market as solution" (Liverman 2009), which positions market instruments as the best and most cost-effective way to mitigate climate change and meet emission requirements set by the Kyoto Protocol. However, a growing literature, particularly within political ecology, 
argues that current carbon offset efforts produce myriad problematic outcomes. The commodification of carbon through market mechanisms may potentially reproduce and exacerbate local injustices; restrict access to natural resources for resource-dependent communities; recentralize natural resource governance, which may lead to evictions, land right violations, and damaged livelihoods; and create a form of neocolonialism-carbon colonialism - which limits the Global South's use of their natural resources so that the North may rectify past emissions and continue current ones (Bumpus \& Liverman 2011; Buhaug et al. 2010; Finley-Brook \& Thomas 2011; Lohmann 2008; Phelps et al. 2010). A related question is who benefits and who bears the costs of the rapidly expanding carbon economy (Boyd et al. 2011). Carbon offset mechanisms allow rich nations or corporations to dominate the current carbon market, outcompeting those who cannot afford to buy carbon credits and thereby restricting poorer nations' future pathways to growth and development (Bumpus 2011). Meanwhile, the purchase of carbon offsets by industries and nations in the Global North allows these actors to continue polluting and fails to encourage them to move away from the use of carbon-based fuels, resulting in continued emissions (Bond 2012).

Currently, there are two major mechanisms for carbon offsets at the international level, "Reduced Emissions from Deforestation and Forest Degradation" (REDD+) and the Clean Development Mechanism (CDM). The implications of these for climate justice have sparked increasing debate and attention in the geography literature. REDD+ is an emission reduction strategy that emerged out of the UNFCCC and was adopted at the $13^{\text {th }}$ session of the Conference of the Parties (COP) to the UNFCCC in Indonesia in 2007 (Thompson et al. 2011). It is intended to create positive economic incentives for reducing carbon emissions from deforestation and degradation in developing countries, while also promoting conservation, sustainable forest management, and the enhancement of forest carbon stocks through reforestation and afforestation (UNFCCC 2008, p.8). Further, REDD+ is being promoted as a means to decrease poverty, enhance biodiversity, facilitate the maintenance and growth of ecosystem services provided by forests, and draw developing nations into climate change negotiations. While REDD+ holds promise, it has been criticized for increasing injustices against forest-dependent communities through increased state and expert control over forests; support for fortress conservation principles; violations of land tenure, access, and territory rights; and unequal contracts, land grabs and land speculation (Buhaug et al. 2010; Phelps et al. 2010). It has also been criticized for resulting in a resurgence of injustices tied to struggles among local actors over access to and governance of natural resources (Phelps et al. 2010). Some scholars see REDD+ as a fundamental shift away from community-based natural resource management back to a system of protectionism and ecosystem enhancement often associated with expanded local injustices (Beymer-Farris \& Basset 2011).

Beymer-Farris and Basset (2011) have empirically demonstrated many of the above concerns in a REDD-readiness project in Tanzania. Through an ahistorical misreading of the landscape in the Rufiji Delta, national and global actors positioned local inhabitants as recent migrants destroying what were once un-peopled forests, and legitimized themselves to undertake carbon forestry projects. As such, control over access to and management of forest resources is shifting from local to national and global actors, resulting in plans to evict locals from the forest to pursue REDD+ goals. This is enabled by discourses that frame climate change as so urgent that it requires immediate intervention. Further, they show that the Rufiji had 
limited participation in the decision-making process (Marino \& Ribot 2012). This case study demonstrates the interlinked nature of all three justice types: distributive, procedural, and recognition.

The distribution of REDD+ burdens can also play out in more subtle ways than eviction, with exclusion from the benefits of land occurring through multiple pathways. For example, smallholders in Chiapas, Mexico have been able to retain land rights while involved in a carbon forestry project. However, they have lost out on the short-term benefits they once derived from their land (e.g., crop production), which have been replaced by the longer-term benefits of carbon sequestration. In response to this loss, farmers moved their subsistence land to new more distant areas, thus increasing their labor burden and forcing them to incur transportation time costs. Additionally, the labor requirements of carbon forestry are causing a movement away from subsistence activities altogether (Osborne 2011).

As Forsyth (2010) has argued, cautionary warnings and examples such as those reviewed here should not be construed as hard evidence that REDD+ will inevitably fail. Indeed, REDD+ is just beginning and positive examples of implementation do exist (e.g., Wilson 2009). In order to drive the process in a way that is sensitive to the varying capabilities, objectives, and values of stakeholders, the arguments and empirical evidence presented here point to the need for careful attention to be paid to land rights and resource access, the distribution of the benefits and burdens of implementation, and participatory inclusion of multiple actors at multiple scales of governance (Forsyth 2010).

The Clean Development Mechanism, the second major international mechanism for carbon offsets, arose out of Kyoto in 1997, and the rules governing CDM were further developed at the $7^{\text {th }}$ session of the COP to the UNFCCC in Marrakech, Morocco in 2001. The purpose of the CDM is twofold. It is designed to both reduce carbon emissions from developed countries and foster sustainable development projects in developing countries. CDM projects acquire carbon credits by reducing GHG emissions through various technological interventions (e.g., hydroelectric dams, biofuels projects, cleaner burning cook stoves). These carbon credits then flow back to the projects' financiers and can be used or traded on the international carbon market (Bumpus 2011). These principles were laid out in the $12^{\text {th }}$ article of the Kyoto Protocol. The Marrakech Accords made it clear that it was the responsibility of the host country to determine if a project meets sustainable development goals (UNFCCC 2002), as well as determining rules for baselines, additionality, equivalences, and leakage. Thus, CDM was designed in part to address the justice concerns articulated in the global arena around the rights of developing countries to pursue development goals. CDM implementation helped overcome conflicts among state actors by resolving the pitting of developed country emission reduction concerns against developing country poverty alleviation concerns.

The distribution of CDM projects around the world has been uneven (Boyd et al. 2009). The associated benefits often flow to countries whose energy use is most inefficient or with high carbon sink potential (Bumpus \& Cole 2010), raising equity concerns over the distribution of benefits among developing countries. Climate justice concerns related to overall program design, the processes by which CDM projects are implemented, and their on-the-ground outcomes have been noted within countries as well (Boyd \& Goodman 2011). For instance, projects may lead to unequal distribution of benefits through interactions with local social relations and the environment, exacerbating income disparities among households and 
communities (Bumpus 2011). CDM projects also run the risk of privileging climate profits over development benefits as financiers seek to maximize carbon offset values (Simon et al. 2012). Given that most host countries lack the market power to have an effect on the price for emission reductions in the global market, an incentive may exist for host countries to undercut each other by lowering sustainable development standards and requirements in order to attract projects (Kelly \& Helme 2000). A lack of incentive for either developed or developing countries to put in place strict sustainable development criteria means that it is likely that projects will focus on emission reductions over development (Sutter \& Parreño 2007). Indeed, several researchers have shown that many existing CDM projects are meeting emissions targets while failing to meet claims of sustainable development (Boyd et al. 2009; Sutter \& Parreño 2007). Problems defining what exactly constitutes sustainable development have also contributed to this failure (Boyd et al. 2009). Finally, the differential power relations that exist between various social actors involved in a CDM process can result in human rights abuses; violations of international standards concerning free, prior, and informed consent; limitations on the opportunity for impacted communities to voice their concerns about CDM projects; and locally unwanted development interventions (Finley-Brook \& Thomas 2011).

From a scalar perspective, the governance structures of both REDD+ and CDM lead to procedural, distributive, and recognition justice issues. Currently, the primary movers of REDD+ are UN-REDD, comprised of several UN organizations, and the World Bank's Forest Carbon Partnership Facility, which negotiates and implements REDD+ standards and projects with state actors. Thus, REDD+ is governed by international institutions, and the state is "primary apparatus" for carrying out projects. This setup subsumes localized interests into the state, homogenizing local actors and civil society (Thompson et al. 2011). Similar problems exist for the CDM. By allowing states to determine development goals, local actors may be excluded from the decision-making table and local needs subsumed under the interests of the state. The pursuit of sustainable development within CDM is thus context-specific and dependent on the development priorities of institutions, states, market demands, and the stakeholders included in the decision-making process (Bumpus \& Cole 2010). While mechanisms within CDM such as the Gold Standard contribute to ensuring that locally relevant development is pursued, Bumpus and Cole (2010) have criticized it for overlooking the procedural necessity of engaging poor and marginalized stakeholders in project implementation and instead relying on a "tick-box" approach.

Regardless of the mechanism for carbon offsets (REDD+, CDM, or an alternative), project management creates new governmentalities with potential justice implications that need to be examined (Bumpus \& Liverman 2011). Many geographers consider it critical that a political ecology of carbon markets and offsets continue to be developed to examine: 1) how carbon outcomes are defined and controlled through a structure of discourse that determines frames and priorities; 2) how scientific expertise, through discourse and representation, work together to produce particular climate problems and outcomes; and 3) how language, science, institutions, and culture that shape the discourse of climate change can be used to further political objectives in order to gain a more complete understanding of the potential justice problems posed by carbon offset projects (Bumpus \& Liverman 2011; Forsyth 2003; Lovell \& Liverman 2010; Peet et al. 2011). 


\section{Justice and Adaptation Action}

Early global discourse on climate change avoided discussions of adaptation as a type of climate action as it was seen as contributing to 'local' well-being but not to the 'global' good of mitigation (Ayers \& Dodman 2010). Over the last decade, adaptation has emerged as a key policy response at the global level as a result of recognition that climate change impacts are already occurring and that those who are most vulnerable need to adapt regardless of mitigation efforts. This shift was also the result of an increased recognition that adaptive capacity is linked to levels of development and that supporting development in turn supports adaptation (Ayers \& Dodman 2010).

Similar to the justice problems posed by mitigation efforts, funding climate actions on adaptation through existing global governance structures presents potential justice problems. Who gets and controls the funds fundamentally shapes justice outcomes (Roberts 2009). Many of these problems are caused by what has been referred to as the "adaptation paradox," which arises from the fact that climate change is a global risk being governed globally, but vulnerability and impacts are felt locally (Ayers 2011). Distributive problems become particularly apparent within the debate on adaptation as the countries least responsible for climate change will be the most affected by it. This leads to difficult questions, all with justice implications: i) who is responsible for the costs; ii) who should receive help adapting; and iii) what should be adapted to and how?

Hartzell-Nichols (2011) provides a poignant example that draws out the dilemmas inherent in these three questions. If a small boy living in a town affected by rising sea levels in Bangladesh in 2040 dies owing to a lack of freshwater resulting from salt water intrusion and the impact of flooding on water infrastructure, to what extent is climate change responsible? And if we recognize that it is difficult to distinguish many of the adaptive actions that could have been taken to prevent this situation (e.g., improving health services to make better medical assistance available or moving to higher ground) from the normal course of development or domestic policy, who then is responsible for bearing the costs?

Three broad ways of looking at who should bear the costs of adaptation have emerged: those historically responsible for emissions should pay; those with the highest ability should pay; and all should pay equally (Hartzell-Nichols 2011). Theoretical convergence has centered on wealthy nations responsible for historical emissions as being responsible for adaptation costs, while in practice the largest emitters and states with the greatest means have been given responsibility (Hartzell-Nichols 2011).

The questions of who should receive adaptation funding and how it should be allocated (and therefore what should be adapted to and how) are driven by the concept of vulnerability, as discussed in Part 1 of our review. Typically, scholars have acknowledged that a just allocation of funds needs to be based on both physical and social vulnerability (Grasso 2010), which are highly uneven within countries, communities, and even households. In practice, developed countries are committed to assisting countries labeled (as a whole) as particularly vulnerable, through funding mechanisms including the Adaptation Fund under the Kyoto Protocol of the UNFCCC and the Pilot Program for Climate Resilience (PPCR) administered by the World Bank. Reliance on the concept of vulnerability to make funding decisions means that the way vulnerability is defined and measured, and by whom, become central justice concerns (Klein and Mohner 2011). 
To illustrate, the UNFCCC ${ }^{1}$ has a limited view of what constitutes adaptation (Ayers \& Dodman 2010) and its current approach to funding adaptation limits both the types of actions that can be taken as well as where (Huq \& Burton 2003). The UNFCCC requires that adaptation funds be directed at actions addressing future climate change as opposed to current climate variability. The UNFCCC also regards adaptive actions as responses to the "additional" burdens caused by climate change, thus locating risk within the biophysical changes taking places in the atmosphere rather than the on-the-ground realities that cause people to be vulnerable or unable to adapt in the first place. This impacts-based approach to adaptation (Ayers 2011) has led to a situation in which adaptive actions can only be taken in response to known anthropogenic climatic changes and must be shown to be above and beyond baseline development needs (Ayers \& Dodman 2010). But distinguishing between "additional" and "baseline" is highly problematic. Ayers and Huq (2008) describe the situation as "absurd," as many countries are unable to address their "baseline" development needs, on which "additional" adaptation needs would need to be built.

Further, using an impacts-based approach to adaptation has meant that technical and scientific expertise is needed to define and predict climate problems and formulate adaptive solutions (Ayers 2011). As a result, priority has been given to technological solutions, such as dams, irrigation schemes, and early warning systems (Klein 2008), meaning that local knowledge and needs may be excluded from the decision-making process in favor of technoscientific expertise (Few et al. 2007). Ayers (2011) shows that expert-driven processes tend to aggregate the local in such a way that community participation is achieved through an invitation process where representatives stand in for an entire community. This approach will likely involve community elites but silence the majority of community members who are likely to be most vulnerable. To achieve climate justice, participation of local people and not just local elites in a deliberative decision-making process is crucial for ensuring that adaptation planning considers how risk is experienced locally and that funded responses are appropriate (Ayers 2011). Decisions of how to adapt may also promote injustice by widening income gaps or deepening vulnerability through limiting livelihood diversification strategies and creating path dependencies (Thomas \& Twyman 2005).

To address the justice concerns associated with climate adaptation actions, Grasso (2010) has developed a framework for evaluating the procedural and distributive justice aspects of several current and proposed international funding instruments. Applying this framework, he argues that distributive justice concerns are well addressed in terms of (1) recognizing common but differentiated responsibility for burden sharing, and (2) ensuring that capabilities are taken into account with regards to allocating funding. In contrast, in considering procedural justice, only inclusiveness is incorporated, while recognition and balances of power are ignored. It is important to note that, like much of the climate justice literature outside of geography, Grasso positions states as the "rightful recipients of justice"

\footnotetext{
${ }^{1}$ Note that alternatives to the UNFCCC for adaptation support have recently developed as a response to what is thought to be the inadequacy of the UNFCCC to respond to the adaptation needs of developing countries. For example, the PPCR takes a much broader view of adaptation. PPCR funds are designed to build climate resilience through development. However, an initial review of PPCR activity by Ayers et al. (2011) shows that an impactsbased ideology rather than development indicators still dictates country selection and the PPCR funds do little better in addressing underlying non-climatic vulnerabilities.
} 
and as the actors in the best position to direct individual behavior to deal with climate issues. But, as we emphasize, empirical analysis of justice issues with states as their objects masks the ways that justice issues play out between state and local actors and among different local actors.

Related to the justice outcomes of an impacts-based approach to adaptation are the discursive problems with the use of the adaptation concept itself. Ribot (2011) argues that the use of the term locates attention on climate hazards rather than the overall set of stressors people face and shifts discussion away from cause to response. Such framing also naturalizes the process of adaptation and runs the risk of reproducing a form of social Darwinism in which those who do not adapt are seen as unfit. Arguably, this frame masks the social, political, and economic processes driving change in the first place and places the burden of adaptation on individuals.

Finally, if we consider here adaptation more broadly, in terms of adaptive responses to current and anticipated climate change, we must also then consider the justice implications of recent large-scale land acquisitions in the Global South, often termed "land grabs." Some land grabs are linked to carbon offset projects (e.g., under REDD+, as detailed earlier), but many are related to anticipated land needs for agricultural or biofuels production, other planned countryscale climate change adaptations, or as speculative investments (Borras et al. 2011; Zoomers 2010). Although we will not review this literature in any greater detail here, many geographers are conducting empirical research in this area and we believe it is an important emerging topic of climate justice.

\section{Final Reflections}

In this two-part review, we have presented a synthesis of the recent literature on climate justice as related by and relevant to geographic scholarship. Here in Part 2, themes that emerge as particularly important are (1) the distribution of the burdens of climate actions, beyond who finances these actions; and (2) scale interactions, among international entities, states, communities, households, and individuals. Within these themes, the field of geography has much to offer to the debate on climate justice. Geographers have a well-established tradition of exploring aspects of structure, agency, and adaptation in smallholder agricultural systems or natural-resource-dependent communities in the Global South, particularly in the context of conservation and/or development projects. Access to and control over environmental decision-making processes has long been the purview of geographic inquiry. The field of political ecology, in particular, plays an important role in drawing out the justice concerns that arise from the scientific and policy-making discourses that frame the debate over climate change action and solutions in the public sphere. While our two-part review does not encompass all climate justice scholarship, its directed approach to drawing out the geographic contributions in particular, as well as other key contributions, allows us to identify the broad contours of the climate justice literature of greatest interest to geographers. By presenting an organizational structure to the literature, the authors hope this two-part review expands the climate change justice discussion and presents, at the very least, a compass for future navigation.

In Part 1, we argued that insufficient attention has been paid to questions of procedural climate justice. The existing literature leans heavily on the procedural role of state actors, with 
less attention given to other types of actors. We believe there is a critical need for research that focuses on procedural justice on the local scale. Determining not only what constitutes climate justice claims, but also who makes them and how they do so is imperative. We also argued that the production of just climate outcomes at various scales necessitates a comprehensive theory of justice that takes into account all types of justice, distributive, procedural, and recognition. In particular, the concept of recognition justice is still largely missing in climate justice scholarship.

Here in Part 2, our synthesis demonstrates the concept of scale is critical to illuminating the injustices that arise not only from the uneven effects of climate change, but also from the uneven effects of the attendant human responses. Scale is important to the consideration of climate justice in both key ways conceptualized by geographers-scale as an epistemological analytical choice (i.e., unit of analysis) and scale as ideologically produced through material practice (i.e., scalar politics). Our review has identified two issues of scale in particular. First, it is important to determine the appropriate scales at which solutions are to be formulated and implemented, and to be responsive to the potential injustices that arise when processes occurring at one scale affect outcomes at other scales. Second, how to determine who receives funds for climate actions is linked to the scale at which assessments and decisions are made. In Part 1, we highlighted how broad scale vulnerability assessments will likely mask differentiated impacts at local levels. In Part 2, we highlight how the current structure of mitigation projects and distribution of adaptation funds may promote injustice, deepen vulnerability, and put local actors into an even less advantaged position.

Despite the significant role scale plays within all three categories of climate justice (characterization, impacts, and responses) covered in both Parts 1 and 2, our review suggests that the difficulties of crossing analytical scales (and of conceptualizing scale as ideologically produced) are not yet integral to and explicit in climate justice debates. Our review also suggests a scalar disjuncture in the climate justice literature. More specifically, apart from questions on the commodification of carbon, scholars commonly focus on one scale of analysis separately from the other scales of investigation. In this regard, Barrett (2012) argues that we need a multi-scalar construct for analyzing climate justice. Current analysis of international negotiations, for example, often fails to scale down to the local level, while empirical studies documenting injustices at the community or household level often fail to scale up to the national or international level. Bridging this scalar divide presents a clear challenge to the comprehensive resolution of current climate justice dilemmas - a challenge which geographers are uniquely situated to address. The recently published Spaces of Environmental Justice (Walker 2010), which brings the question of intersecting scales to the forefront, could provide a model for geographers' engagement in climate justice.

Finally, our review argues that mismatches in scales of both analysis and climate action lead to problematic justice outcomes in which the "local" is subsumed into both the "national" and the "global." Current framing of climate justice as a question among state actors has had a veiling effect at more local scales (in terms of analysis) and has led to a number of climate justice paradoxes, such as those associated with REDD+ and CDM. Geographers are carrying out scholarly work across the climate justice realms as outlined in this two-part review, but they are truly at the forefront of empirical research exposing these cross-scalar justice contradictions. 


\section{Reference List}

Ayers, J. (2011). Resolving the adaptation paradox: exploring potential for deliberative adaptation policy-making in Bangladesh. Global Environmental Politics 11(1), pp. 62-88.

Ayers, J. and Dodman, D. (2010). Climate change adaptation and development I: the state of the debate. Progress in Development Studies 10(2), pp. 161-168.

Ayers, J. and Huq, S. (2008). Supporting adaptation to climate change: what role for development assistance? Presented at DSA Annual Conference 2008 'Development's Invisible Hands: Development Futures in a Changing Climate.' 8th November 2008, Church House, Westminster, London.

Ayers, J., Kaur, N. and Anderson, S. (2011). Negotiating climate resilience in Nepal. IDS Bulletin 42(3), pp. 70-79.

Barrett, S. (2012). The necessity of a multiscalar analysis of climate justice. Progress in Human Geography. DOI 10.1177/0309132512448270, preprint online version

Beymer-Farris, B. and Basset, T. (2011). The REDD menace: resurgent protectionism in Tanzania's mangrove forests. Global Environmental Change, 22, pp. 332-341.

Bond, P. (2012). Emissions trading, new enclosures, and eco-social contestation. Antipode 44(3), pp. 684-701.

Borras Jr., S., Hall, R., Scoones, I., White, B. and Wolford, W. (2011). Towards a better understanding of global land grabbing: an editorial introduction. The Journal of Peasant Studies 38(2), pp. 209-216.

Boyd, E., Boykoff, M. and Newell, P. (2011). The new carbon economy: what's new? Antipode 43(3), pp. 601-611.

Boyd, E. and Goodman, M. (2011). The clean development mechanism as ethical development?: reconciling emissions trading and local development. Journal of International Development 23(6), pp. 836-854.

Boyd, E., Hultman, N., Roberts, J., Corbera, E., Cole, J., Bozmoski, A., Ebeling, J., Tippman, R., Manna, P., Brown, K. and Liverman, D. (2009). Reforming the CDM for sustainable development: lessons learned and policy futures. Environmental Science \& Policy 12, pp. 820831.

Buhaug, H., Gleditsch, N., and Theisen, O. (2010). Implication of climate change for armed conflict. In Mearns, R. and Norton, A., (eds.), Social dimensions of climate change: equity and vulnerability in a warming world. Washington, DC: The World Bank, pp. 75-101.

Bumpus, A. (2011). The matter of carbon: understanding the materiality of $\mathrm{tCO}_{2} \mathrm{e}$ in carbon offsets. Antipode 43(3), pp. 612-638.

Bumpus, A. and Cole, J. (2010). How can the current CDM deliver sustainable development? Wiley Interdisciplinary Reviews: Climate Change 1(4), pp. 541-547.

Bumpus, A. and Liverman, D. (2011). Carbon colonialism: offsets, greenhouse gas reductions, and sustainable development. In Peet, R., Robbins, P. and Watts, M., (eds.), Global political ecology. New York: Routledge, pp. 203-224.

Farbotko, C. and Lazrus, H. (2012). The first climate refugees? Contesting global narratives of climate change in Tuvalu. Global Environmental Change 22 (2), pp. 382-390.

Few, R., Brown, K. and Tompkins, E. (2007). Public participation and climate change adaptation: avoiding the illusion of inclusion. Climate Policy 7(1), pp. 46-59. 
Finley-Brook, M. and Thomas, C. (2011). Renewable energy and human rights violations: illustrative cases from indigenous territories in Panama. Annals of the Association of American Geographers 101(4), pp. 863-872.

Forsyth, T. (2003). Critical political ecology: the politics of environmental science. New York: Routledge.

Forsyth, T. (2010). Forest and climate change policy: what are the costs of inaction? IDEAS reports - special reports, Kitchen, N. (ed.) SR004. LSE IDEAS, London School of Economics and Political Science, London, UK, pp. 22-35.

Grasso, M. (2010). An ethical approach to climate adaptation finance. Global Environmental Change 20(1), pp. 74-81.

Hartzell-Nichols, L. (2011). Responsibility for meeting the costs of adaptation. Wiley Interdisciplinary Reviews: Climate Change 2(5), pp. 687-700.

Huq, S. and Burton, I. (2003). Funding adaptation to climate change: what, who and how to fund? Sustainable Development Opinion Paper, London: IIED.

Kelly, C. and Helme, N. (2000). Ensuring CDM project compatibility with sustainable development goals. Washington D.C.: Center for Clean Air Policy.

Klein, R.J.T. (2008). Mainstreaming climate adaptation into development policies and programmes: a European perspective. In Bursi, C. (ed.) Financing climate change policies in developing countries. Brussels: European Parliament, pp. 38-51.

Klein, R. and Mohner, A. (2011). The political dimensions of vulnerability: implications for the Green Climate Fund. IDS Bulletin 42(3), pp. 15-22.

Kythreotis, A. (2011). Progress in global climate change politics? Reasserting national state territoriality in a 'post-political' world. Progress in Human Geography, 36 (4), pp. 457-474. Liverman, D. (2009). Conventions on climate change: constructions of danger and the dispossession of the atmosphere. Journal of Historical Geography 35(2), pp. 279-296. Lohmann, L. (2008). Carbon trading, climate justice, and the production of ignorance: ten examples. Development 51(3), pp. 359-365.

Lovell, H. and Liverman, D. (2010). Understanding carbon offset technologies. New Political Economy 15(2), pp. 255-273.

Marino, E. and Ribot, J. (2012). Adding insult to injury: climate change and the inequities of climate intervention. Global Environmental Change 22(2), pp. 323-328.

Osborne, T. (2011). Carbon forestry and agrarian change: access and land control in a Mexican Forest. The Journal of Peasant Studies 38(4), pp. 859-883.

Peet, R., Robbins, P. and Watts, M. (2011). Global political ecology. New York: Routledge. Phelps, J., Webb, E. and Agrawal, A. (2010). Does REDD+ threaten to recentralize forest governance? Science 328, pp. 312-313.

Ribot, J. (2011). Vulnerability before adaptation: towards transformative climate action. Global Environmental Change 21, pp. 1160-1162.

Roberts, J. (2009). The international dimension of climate justice and the need for international adaptation funding. Environmental Justice 2, pp. 185-190.

Simon, G., Bumpus, A. and Mann, P. (2012). Win-win scenarios at the climate-development interface: challenges and opportunities for stove replacement programs through carbon finance. Global Environmental Change. 22(1), pp. 275-287. 
Sutter, C. and Parreño, J. (2007). Does the current Clean Development Mechanism (CDM) deliver its sustainable development claim? An analysis of officially registered CDM projects.

Climatic Change 84, pp. 75-90.

Thomas, S. and Twyman, C. (2005). Equity and justice in climate change adaptation amongst natural-resource-dependent societies. Global Environmental Change 15, pp.115-124.

Thompson, M., Baruah, M. and Carr, E. (2011). Seeing REDD+ as a project of environmental governance. Environmental Science and Policy 14, pp. 100-110.

UNFCCC (2002). The Marrakech Accords. Report on the Conference of the Parties on its Seventh Session, held at Marrakech from 29 October to 10 November 2001, FCCC/CP/2002/13.

UNFCCC. (2008). Report of the Conference of the Parties on its thirteenth session, held in Bali from 3 to 15 December 2007.

Walker, G. (2010). Beyond distribution and proximity: exploring the multiple spatialities of environmental justice. In Holifield, R., Porter, M. and Walker, G., (eds.), Spaces of

environmental justice, United Kingdom: Wiley-Blackwell, pp. 22-46.

Wilson, E. (2009). Company led approaches to conflict resolution in the forest sector. The Forests Dialogue, number four. Connecticut: USA.

Zoomers, A. (2010). Globalisation and the foreignisation of space: seven processes driving the current global land grab. The Journal of Peasant Studies 37(2), pp. 429-447. 